University of New Hampshire

University of New Hampshire Scholars' Repository

Faculty Publications

$6-1-2000$

\title{
Coupled Atmosphere-Biophysics-Hydrology Models for Environmental Modeling
}

\author{
Robert L. Walko \\ Colorado State University \\ Larry E. Band \\ University of North Carolina \\ Jill Baron \\ Colorado State University \\ Timothy G. F. Kittel \\ National Center for Atmospheric Research \\ Richard B. Lammers \\ University of New Hampshire, Durham, richard.lammers@unh.edu
}

See next page for additional authors

Follow this and additional works at: https://scholars.unh.edu/faculty_pubs

\section{Comments}

This is an article published by American Meteorological Society in Journal of Applied Meteorology and Climatology in 2000, available online: https://dx.doi.org/10.1175/1520-0450(2000)039<0931:CABHMF>2.0.C0;2

\section{Recommended Citation \\ Walko, R.L., L.E. Band, J. Baron, T.G.F. Kittel, R. Lammers, T.J. Lee, D. Ojima, R.A. Pielke Sr., C. Taylor, C. Tague, C.J. Trembeck and P.L. Vidale (2000) Coupled Atmosphere-Biophysics-Hydrology Models for Environmental Modeling, Journal of Applied Meteorology, 39:931-944.}

This Article is brought to you for free and open access by University of New Hampshire Scholars' Repository. It has been accepted for inclusion in Faculty Publications by an authorized administrator of University of New Hampshire Scholars' Repository. For more information, please contact Scholarly.Communication@unh.edu. 


\section{Authors}

Robert L. Walko, Larry E. Band, Jill Baron, Timothy G. F. Kittel, Richard B. Lammers, Tsengdar J. Lee, Dennis S. Ojima, Roger A. Pielke Sr., Chris Taylor, Christina L. Tague, Craig J. Tremback, and Pier Luigi Vidale 


\title{
Coupled Atmosphere-Biophysics-Hydrology Models for Environmental Modeling
}

\author{
Robert L. Walko,* LARry E. Band, + Jill Baron,\# Timothy G. F. KitTel, @ Richard Lammers, \& \\ Tsengdar J. Lee, ** Dennis Ojima, \# Roger A. Pielke Sr., ${ }^{*}$ Chris TaYlor, ++ Christina Tague, \#\# \\ Craig J. Tremback, @ AND Pier Luigi Vidale* \\ * Department of Atmospheric Science, Colorado State University, Fort Collins, Colorado \\ + Department of Geography, University of North Carolina, Chapel Hill, North Carolina \\ \# Natural Resource Ecology Laboratory, Colorado State University, Fort Collins, Colorado \\ @ National Center for Atmospheric Research, Boulder, Colorado \\ $\&$ Complex Systems Research Center, University of New Hampshire, Durham, New Hampshire \\ ** PRC, McLean, Virginia \\ ++ Institute of Hydrology, Wallingford, Oxfordshire, United Kingdom \\ \#\# Department of Geography, University of Toronto, Toronto, Ontario, Canada \\ @@ ASTER Division, Mission Research Corporation, Fort Collins, Colorado
}

(Manuscript received 9 July 1998, in final form 15 June 1999)

\section{ABSTRACT}

\begin{abstract}
The formulation and implementation of LEAF-2, the Land Ecosystem-Atmosphere Feedback model, which comprises the representation of land-surface processes in the Regional Atmospheric Modeling System (RAMS), is described. LEAF-2 is a prognostic model for the temperature and water content of soil, snow cover, vegetation, and canopy air, and includes turbulent and radiative exchanges between these components and with the atmosphere. Subdivision of a RAMS surface grid cell into multiple areas of distinct land-use types is allowed, with each subgrid area, or patch, containing its own LEAF-2 model, and each patch interacts with the overlying atmospheric column with a weight proportional to its fractional area in the grid cell. A description is also given of TOPMODEL, a land hydrology model that represents surface and subsurface downslope lateral transport of groundwater. Details of the incorporation of a modified form of TOPMODEL into LEAF-2 are presented. Sensitivity tests of the coupled system are presented that demonstrate the potential importance of the patch representation and of lateral water transport in idealized model simulations. Independent studies that have applied LEAF-2 and verified its performance against observational data are cited. Linkage of RAMS and TOPMODEL through LEAF-2 creates a modeling system that can be used to explore the coupled atmosphere-biophysicalhydrologic response to altered climate forcing at local watershed and regional basin scales.
\end{abstract}

\section{Introduction}

As experience with numerical modeling of atmospheric processes has progressed over the decades, the atmospheric modeling community has come to recognize that various aspects of the atmosphere-ecosystemocean system that once were thought to play a relatively minor role are actually very important in atmospheric circulations. Ecosystem and soil processes and their effect on the atmosphere are certainly in this category. Most mesoscale and global atmospheric models of 20 years ago either ignored or treated in an extremely simple manner interactions of the atmosphere with underlying soil and vegetated surfaces. Now, field and modeling studies have demonstrated that these interactions are extremely important in both long-term climate sim-

Corresponding author address: Robert L. Walko, Department of Atmospheric Science, Colorado State University, Fort Collins, CO 80523-1371.

E-mail: walko@tibet.atmos.colostate.edu ulations and short-term weather forecasting applications (Dickinson 1995; Pielke et al. 1998). Moreover, recent numerical studies strongly suggest that land-use change may cause significant weather, climate, and ecosystem change (Chase et al. 1998; Baron et al. 1998; Stohlgren et al. 1998; Pielke et al. 1999). Because the role of these interactions has become recognized, parameterizations of vegetation and soil processes have progressively become more sophisticated over the years in order to treat the complexities of the physical system. Soil-vegetation-atmosphere transfer (SVAT) schemes employed in general circulation, mesoscale, and small-scale atmospheric numerical models have become increasingly sophisticated (Deardorff 1978; Avissar et al. 1985; Dickinson et al. 1986; Sellers et al. 1986; Noilhan and Planton 1989; Mihailovic et al. 1993; Acs 1994; Bosilovich and Sun 1995; Viterbo and Beljaars 1995; Pleim and Xiu 1995). Also, our ability to sense characteristics of the land surface remotely has improved dramatically, enabling much better data to be input to the more sophisticated parameterizations (Loveland et al. 1991; Lee et al. 1995). 
The Land Ecosystem-Atmosphere Feedback model, or LEAF (Lee 1992), is one such SVAT that has been developed at Colorado State University as a component of the Regional Atmospheric Modeling System (RAMS). The current version, LEAF-2, is a representation of surface features that include vegetation, soil, lakes and oceans, and snowcover and their influence on each other and on the atmosphere. LEAF-2 includes prognostic equations for soil temperature and moisture for multiple layers, vegetation temperature, and surface water including dew and intercepted rainfall, snowcover mass, and thermal energy for multiple layers, and temperature and water vapor mixing ratio of canopy air. Exchange terms in these prognostic equations include turbulent exchange, heat conduction, and water diffusion and percolation in the snowcover and soil, longwave and shortwave radiative transfer, transpiration, and precipitation. This paper provides a description of the current version of LEAF-2 and its implementation in RAMS.

A special feature of LEAF-2 is its ability to represent finescale variations in surface characteristics, such as vegetation type, terrain slope, soil type and moisture, or bodies of water, which often vary considerably over short horizontal distances. Each surface type responds to and influences the overlying atmosphere in its own unique way. Atmospheric circulations are often caused by or strongly affected by the spatial variability of surface characteristics (Avissar 1995). Ideally, sufficiently fine computational grids would be employed in atmospheric-biophysical models to resolve both surface features and the full atmospheric response to them. However, computer resources, always a limiting factor in model resolution, normally prevent the ideal simulation from being achieved. Fortunately, LEAF-2 is relatively inexpensive computationally when compared with representation of atmospheric processes in RAMS. The implementation of LEAF-2 within RAMS takes advantage of this fact by allowing multiple surface types to coexist beneath a single grid-resolved column of air. Each surface type or "patch" consists of its own multiple snowcover and soil layers, vegetation, and canopy air (except for water surface patches), and prognostic variables are evaluated for all these components by patch. In this statistical dynamical approach (Avissar and Pielke 1989), all patches interact with the same overlying column of air, each according to its fractional area of coverage.

An obvious benefit of this approach is the ability to fractionally weight several land surface types (e.g., forest, grass, bare soil) rather than characterizing the entire grid cell as having the most prevalent surface type, which may be less than a majority. Another benefit is the ability to treat uniquely for each patch simulated precipitation reaching the ground. For example, rainfall or snowmelt often runs off sloping areas to accumulate in valleys before percolating into the soil, and some moisture that does percolate in sloping areas often tends to flow slowly downslope within the soil. This leads to a relative drying of soil in some areas and moistening in others over horizontal length scales that include the subgrid scale. The resulting effect on subsequent heat and moisture fluxes to the atmosphere can be very different from the case of uniform percolation. In both these examples, nonlinear vegetation response to patchiness in soil moisture and radiative fluxes can further complicate atmosphere-soil-ecosystem interaction.

TOPMODEL (Beven and Kirkby 1979; Beven 1982, 1984, 1986; Hornberger et al. 1985; Sivapalan et al. 1987) is a hydrology model that represents lateral downslope transport of water within saturated regions of the soil. Because water transport in LEAF-2 was originally strictly vertical, coupling between these two models simultaneously represents both vertical and lateral transport, and their interaction. Subsurface water transport is relatively slow, with lateral displacements of tens of meters per day or less; consequently TOPMODEL represents water transports at scales much finer than the typical horizontal grid cell dimension in RAMS. The most appropriate coupling is thus for TOPMODEL to exchange soil moisture between patches rather than between grid cells. Thus, where TOPMODEL is concerned, a patch is identified as a region that either gains or loses soil moisture by lateral transport. Vertical water exchange in LEAF-2 in turn feeds back to the water distribution and computed transport rates in TOPMODEL. A main purpose of this paper is to describe the details of coupling LEAF-2 and TOPMODEL with the aim of combining the strengths of the models. TOPMODEL has previously been coupled with SVAT schemes, for example, by Famiglietti and Wood (1991, 1994), Band (1993), Band et al. (1993), Stieglitz et al. (1997), and R. D. Koster, (1998, personal communication).

Careful integration of atmospheric, ecosystem, and surface hydrological models can provide a simulation system for evaluating the sensitivity of regional ecosystems and water resources to altered global climate forcing and local land use changes (Pielke et al. 1997). Following is a description of LEAF-2 and TOPMODEL, details of their coupling, sensitivity tests demonstrating the potential importance of subgrid patches and TOPMODEL transport in RAMS/LEAF-2 simulations, and citation of recent applications of LEAF-2 that have been verified with observational data.

\section{Description of LEAF-2}

This section summarizes the formulation of LEAF-2, highlighting changes and new features added since the original LEAF model (Lee 1992; Lee et al. 1995), which include subgrid patch representation, prognostic snowcover, treatment of freezing and thawing of soil, and local runoff of heavy precipitation and snowmelt. 


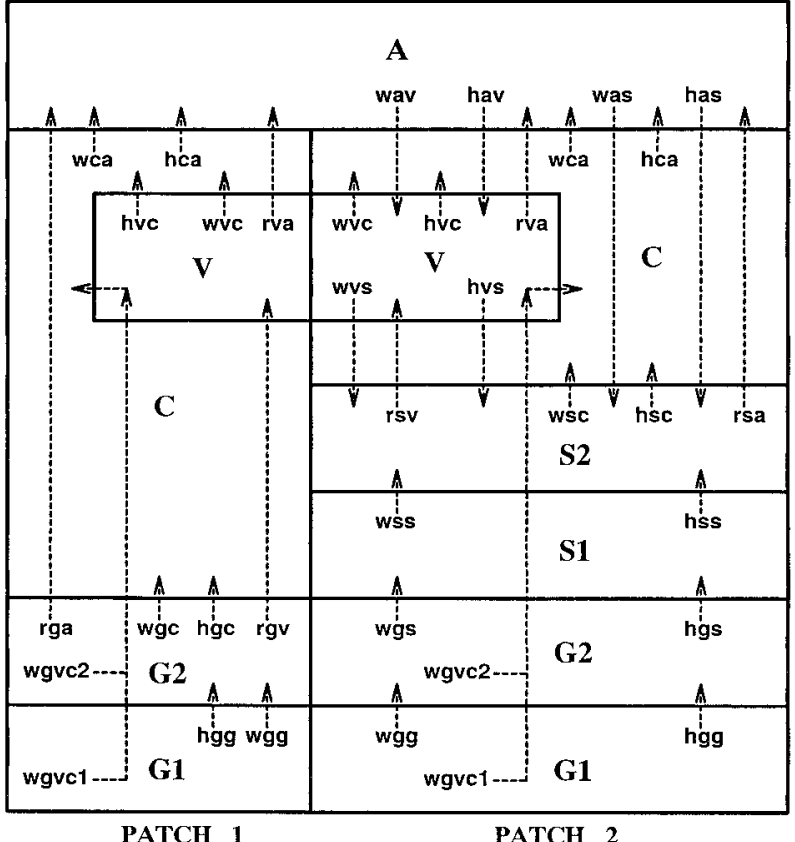

FIG. 1. Schematic of heat and moisture transfer between components of LEAF-2 for two patches within a model grid cell. The free atmosphere, canopy air, vegetation, snow, and ground (soil) are represented by the letters A, C, V, S, and G, respectively. Patch 2 contains snow cover, and patch 1 does not. See text for description of arrow labels.

\section{a. Principal components}

LEAF-2 is a representation of energy and moisture budgets for soil, vegetation, canopy air, temporary surface water (e.g., snowcover), and permanent water bodies, and the exchange of energy and moisture with the atmosphere. Soil and snowcover are divided into multiple vertical levels, and vegetation and canopy air are represented by a single level. A given surface grid cell is divided horizontally into multiple subgrid patches, each with its own vegetation, canopy air, and soil and snow layers, or with a permanent water body. There is no spatial relationship between patches; each represents the fractional area of the grid cell that is occupied by its particular surface type without regard to location in the grid cell.

Conservation equations for energy and moisture are applied to vegetation, canopy air, and each soil and snowcover layer in each patch of a grid cell, and include a storage term for each of these components and parameterization of fluxes between them. The LEAF-2 components (except for permanent water bodies) and the flux pathways between them are illustrated in Fig. 1. This example contains two patches beneath an atmospheric column (A), where both patch 1 and patch 2 have partial vegetation cover (V), and patch 2 alone has (two layers of) snowcover $(\mathrm{S})$. Two soil layers $(\mathrm{G})$ and canopy air (C) are also shown.

Fluxes are denoted by terms of the form $F_{h g s}$, where
$F$ stands for flux (although for clarity the $F$ is not included in Fig. 1), the first subscript ( $w, h$, or $r$ ) indicates whether the flux is water transfer, heat transfer (by turbulent exchange, conduction, or precipitation) or longwave radiative transfer, and the second and third subscripts denote the source and receptor, respectively, of the fluxed quantity ( $g$ for ground, $s$ for snow, $v$ for vegetation, $c$ for canopy air, and $a$ for free atmosphere). The one exception in notation is $F_{w g v c}$, which denotes a flux of water from soil to canopy air via the vegetation in the form of transpiration. This is distinguished from the flux $F_{w v c}$, which is a flux of water by means of evaporation from surface vegetation moisture, such as dew or intercepted rain, to the canopy air. Fluxes are defined as positive in the direction of the arrows; negative values imply transport in the opposite sense. Shortwave radiative transfer (not illustrated in Fig. 1) is denoted below as a net amount $S$ received by each component of the system under the combined influence of all others, rather than as fluxes exchanged between the components. Subscripts ( $g$, $s$, and $v$ ) attached to $S$ denote reception by the ground, snowcover, and vegetation, respectively. Numbered subscripts (1 and 2) are added to $S_{s}$ and $F_{w g v c}$ to denote reception by a specific snowcover or soil layer.

\section{b. Soil}

Individual soil layers are normally $3 \mathrm{~cm}$ to perhaps $30 \mathrm{~cm}$ thick and collectively represent the soil to a depth up to a few meters. Moisture flux between layers is parameterized in LEAF-2 based on a multilayer soil model described by Tremback and Kessler (1985). This scheme is a modification of schemes described by Mahrer and Pielke (1977) and McCumber and Pielke (1981) with the various iterative processes removed. Moisture flux is given by

$$
F_{w g g}=-\rho_{w} K_{\eta} \frac{\partial(\psi+z)}{\partial z},
$$

where $\rho_{w}$ is the density of liquid water, $K_{\eta}\left(\mathrm{m} \mathrm{s}^{-1}\right)$ is hydraulic conductivity, $\psi(\mathrm{m})$ is the moisture potential or tension, and $z$ is height $(\mathrm{m})$.

Parameters $K_{\eta}$ and $\psi$ are modeled following either Clapp and Hornberger (1978) or van Genuchten (1980). Consistent with the premise of TOPMODEL, described in text below and references cited therein, hydraulic conductivity in saturated soil, $K_{s}$, is assumed to decrease exponentially with depth in the soil [see Eq. (19)].

Internal energy $\left(\mathrm{J} \mathrm{m}^{-3}\right)$ of moist soil, relative to a reference state of soil and completely frozen moisture both at $0^{\circ} \mathrm{C}$, is prognosed for each soil layer and is defined by

$$
Q_{g}=W_{g} f_{i} C_{i} T_{g}+W_{g} f_{l}\left(C_{l} T_{g}+L_{i l}\right)+C_{g} m_{g} T_{g},
$$

where $T_{g}$ is soil temperature $\left({ }^{\circ} \mathrm{C}\right), f_{i}$ and $f_{l}$ are the ice and liquid water fractions (by mass) relative to total water in the soil, $m_{g}$ and $W_{g}$ are the mass of dry soil 
and water, respectively, in kilograms per cubic meter of total volume (the volume includes water, soil, and air), and $C_{i}, C_{l}$, and $C_{g}$ are the specific heats $\left(\mathrm{J} \mathrm{kg}^{-1} \mathrm{~K}^{-1}\right)$ of ice, liquid, and dry soil particles. Here, $Q_{g}$ is a more general quantity than temperature in that it represents the energy associated not only with temperature but also with the latent heat of fusion. Use of $Q_{g}$ as a prognostic variable automatically includes latent heat of freezing and melting in the soil energy balance equations. Temperature and liquid versus ice fraction are diagnosed from $Q_{g}$ (with knowledge of $W_{g}$ and $m_{g}$ ). Water flux in the soil is incrementally reduced with increasing ice fraction such that frozen soil has zero percolation.

Soil heat flux is given by

$$
F_{\text {hgg }}=-\lambda \frac{\partial T_{g}}{\partial z}+F_{w g g}\left(C_{l} T_{s}+L_{i l}\right),
$$

where thermal conductivity $\lambda\left(\mathrm{J} \mathrm{m}^{-1} \mathrm{~s}^{-1} \mathrm{~K}^{-1}\right)$ is given by

$$
\begin{gathered}
\lambda=e^{-\left[\log _{10}|100 \psi|+2.7\right]} \times 4.186 \times 10^{2} \\
\text { for } \log _{10}|100 \psi| \leq 5.1 \\
\lambda=0.00041 \times 4.186 \times 10^{2} \\
\text { for } \log _{10}|100 \psi|>5.1
\end{gathered}
$$

and is dependent on soil moisture through moisture potential $\psi$. Equation (4) is adapted from Eq. (7) of McCumber and Pielke (1981) for the present use of SI units for $\lambda$ and $\psi$. The last term in Eq. (3) represents internal energy carried with moisture flux.

\section{c. Temporary surface water}

Temporary surface water is defined as precipitation that has reached the ground and has not yet percolated into the ground or run off into a permanent water body (oceans, lakes, permanent rivers). It includes snowcover, snow melt, rainwater, and temporary streams and ponds. If in the form of snowcover, temporary surface water may also be divided into several vertical layers, depending on the depth of snow present. Mass $W_{s}(\mathrm{~kg}$ $\mathrm{m}^{-2}$ ) and internal energy are prognosed for each temporary surface water layer.

In analogy with Eq. (2), internal energy of snowcover in units of Joules per kilogram, relative to a reference state of ice at $0^{\circ} \mathrm{C}$, is defined by

$$
Q_{s}=f_{i} C_{i} T_{s}+f_{l}\left(C_{l} T_{s}+L_{i l}\right),
$$

where $T_{s}$ is temperature expressed in degrees Celsius, $C_{i}$ and $C_{l}$ are specific heats of ice and liquid water ( $\mathrm{J}$ $\left.\mathrm{kg}^{-1} \mathrm{~K}^{-1}\right), f_{i}$ and $f_{l}$ are the ice and liquid water fractions (by mass) of snowcover, and $L_{i l}$ is latent heat of fusion of water. Here, $Q_{s}$ between zero and $L_{i l}$ implies the snowcover contains a mixture of ice and liquid at $0^{\circ} \mathrm{C}$, with the liquid fraction $f_{l}$ given by $Q_{s} / L_{i l}$. The microphysics (Walko et al. 1995; Meyers et al. 1997) and convective parameterizations in RAMS evaluate an in- ternal energy of all precipitation and thereby directly contribute internal energy to the surface water or snowcover.

Mass transfer between snowcover layers and from snowcover to the soil occurs in LEAF-2 by percolation of liquid water, denoted by the fluxes $F_{w s s}$ and $F_{w g s}$. Vapor flux from warmer to cooler layers within the snowcover also occurs in nature, but is neglected here because it is typically weak (Adams and Brown 1983). Vapor flux does carry a significant amount of latent heat, however, along with the sensible heat flux in the presence of a temperature gradient. Following Adams and Brown (1983), LEAF-2 parameterizes these two heat fluxes together from a downgradient diffusion relation that uses a combined diffusion coefficient given by

$$
\begin{aligned}
K_{s}= & \left(1.093 \times 10^{-3}\right) \exp \left(0.028 T_{s}\right) \\
& \times\left[0.03+0.303\left(\rho_{s} \times 10^{-3}\right)-0.177\left(\rho_{s} \times 10^{-3}\right)^{2}\right. \\
& \left.\quad+2.25\left(\rho_{s} \times 10^{-3}\right)^{3}\right]
\end{aligned}
$$

where $\rho_{s}$ is the density of a snowcover layer in kilograms per cubic meter. Additional heat flux is carried as the product $F_{w s s} Q_{s}$ by the percolating liquid water. Net heat flux between snow layers is given by

$$
F_{h s s}=-K_{s} \frac{\partial T}{\partial z}-F_{w s s} Q_{s 2},
$$

and heat flux from snowcover to the soil by

$$
F_{h g s}=-0.5\left(K_{s}+C_{g} \lambda\right) \frac{\partial T}{\partial z}-F_{w g s} Q_{s 1} .
$$

The amount of liquid water that percolates from each snowcover layer is diagnosed each timestep as an excess over the liquid water holding capacity of each snow layer. Fractional liquid water content is first diagnosed in the top layer, and liquid water content exceeding $10 \%$ of the ice mass in the snowcover layer is then percolated to the next lower layer, modifying that layer's values of mass and energy. Liquid water is in turn diagnosed for that layer, and the process is repeated. Excess liquid water diagnosed in the lowest snow layer percolates into the top soil layer, until the soil layer becomes saturated. That which cannot enter the top soil layer remains in the lowest snowcover layer as liquid water or may be treated as runoff as described below. If all temporary surface water is in liquid form, it is represented by only a single layer.

Following the updating of all snowcover layers, an adjustment is performed to the snowcover layers to keep their total number and individual thicknesses within prescribed bounds. The adjustment procedure assures that 1) no snowcover layer will become too thin for stable numerical computation, 2) the total number of snowcover layers will not exceed a specified maximum, 3) the total number of snowcover layers will increase when mass is being added to snowcover, if allowed by 1) and 2) above, in order that snowcover be well resolved, 4) 
the thinnest snowcover layers will be the top and bottom ones, in order to better resolve influences from the soil, canopy air, and radiative fluxes, and 5) multiple snowcover layers will be used only if the "snowcover" contains some ice. The snowcover adjustment consists of a transfer of both $W_{s}$ and $W_{s} Q_{s}$ between layers in a manner that maintains global conservation of mass and internal energy. If so little snowcover exists that prognosis of its internal energy by explicit time differencing may be computationally unstable (in which case snowcover resides in a single layer) an implicit computation is done instead in which the snowcover and top soil layer are brought into thermal equilibrium.

\section{d. Canopy air and vegetation}

In vegetated areas, canopy air is defined as air in close proximity to and influenced by vegetation. Turbulent exchange of heat and moisture between canopy air and vegetation, and vegetation stomatal resistance are represented as in Lee (1992). Formation of dew or frost on vegetation, and a full energy budget for vegetationintercepted precipitation have been added in LEAF-2.

Where snowcover is present, turbulent transfer with vegetation is reduced according to the amount that snow covers the vegetation, and transfer with soil is replaced by transfer with snow. Turbulent fluxes between canopy air and the free atmosphere are based on similarity theory as in Louis et al. (1981).

Turbulent exchange of heat and moisture between canopy air and soil or snowcover is represented as the temperature or vapor difference between them divided by an aerodynamic transfer resistance $r_{d}$. In vegetated areas, $r_{d}$ is weighted between a value derived for dense vegetation and a value for bare soil according to the actual vegetation density (Lee 1992). However, the formula for bare soil has been replaced by

$$
r_{d g}=5 / u_{*} \text {. }
$$

Equation (9) is derived from the work of Garratt (1992, and personal communication), which emphasizes that skin temperature $T_{g}$ of a bare soil surface and roughness height temperature $T_{o}$ have different values in the presence of upward or downward heat flux, a fact ignored in many models. He presented the empirical result for a range of natural surfaces and heat flux values that

$$
T_{o}-T_{g}=\frac{2}{k} T_{*}
$$

where $k$ is the von Kármán constant. Equation (9) is derived by equating temperature flux $-u_{*} T_{*}$ from surface similarity theory with surface flux $\left(T_{g}-T_{o}\right) / r_{d g}$ and combining with Eq. (10).

Weighting $r_{d}$ according to vegetation density provides a continuous variation of $r_{d}$ from the case of dense vegetation to that of bare soil (or snow or permanent water surface). Thus, in the no-vegetation limit, that is, for patches whose surface is bare soil, completely snow- covered, or a permanent water body, we identify the "canopy air" conditions as those applying at surface roughness height $z_{o}$, and continue to route turbulent fluxes of moisture and energy between canopy air and surface and between canopy air and the free atmosphere. This avoids the need for separate formulations of bare and vegetated areas and arbitrarily selecting a threshold vegetation density to separate them.

Surface (skin) temperatures of permanent water bodies are specified from observed or seasonally dependent climatological values. A roughness length for permanent water bodies is based on a parameterized wave height related to the instantaneous local wind speed (Charnock 1955; Garratt 1992).

The effective water vapor mixing ratio of soil, which accounts for soil moisture content and is used to evaluate evaporative flux of soil moisture to canopy air, is computed following Lee and Pielke (1992). Representation of dew or frost formation on soil has been added in LEAF-2 and is based on the larger, saturation value of mixing ratio at the soil surface temperature.

\section{e. Precipitation fluxes}

Convective and bulk microphysical parameterizations in RAMS both produce surface fluxes of moisture and energy due to sedimentation of hydrometeors. These fluxes are partitioned between vegetation and surface water components of LEAF-2 according to vegetation fractional coverage. When moisture content on the surface of vegetation (from a combination of intercepted precipitation and dew formation) exceeds the maximum amount that vegetation can hold, the excess amount is first brought to thermal equilibrium with vegetation by heat transfer and is then shed from vegetation to fall into the surface water category.

\section{f. Radiative fluxes}

Longwave radiation is emitted, absorbed, and reflected by the atmosphere, vegetation, snowcover, soil, and permanent water bodies. Snowcover, even when shallow, acts nearly as a blackbody to longwave radiation. Thus, when snowcover is present, the top snow layer replaces the top soil layer as a radiating and absorbing surface. Soil and vegetation likewise have high emissivities (low reflectivities). LEAF-2 thus makes the assumption that multiple longwave reflections do not occur; once-reflected radiation is assumed to be fully absorbed upon next reaching a surface.

Solar (shortwave) radiation can penetrate to considerable depths into snowcover. LEAF-2 thus considers the transmissivity of each snow layer. Vegetation is assumed to be opaque, however. Defining $R_{S \downarrow}$ as downward shortwave radiation at the bottom of the atmosphere, net shortwave radiation received by vegetation, snowcover layer $i$, and the top soil layer is given, respectively, by 


$$
\begin{aligned}
S_{v} & =R_{S \downarrow} \Gamma_{s}\left[1-\alpha_{v}+\alpha_{s}\left(1-\Gamma_{s}\right)\right], \\
S_{s i} & =R_{S \downarrow}\left(1-\Gamma_{s}\right)\left(1-\alpha_{s}\right)\left(1-\tau_{s}+\tau_{s} \alpha_{g}\right) f_{i},
\end{aligned}
$$

and

$$
S_{g}=R_{S \downarrow}\left(1-\Gamma_{s}\right)\left(1-\alpha_{s}\right) \tau_{s}\left(1-\alpha_{g}\right),
$$

where $\alpha_{v}, \alpha_{s}$, and $\alpha_{g}$ are vegetation albedo, net albedo from all snow layers, and soil albedo; $\tau_{s}$ is net transmissivity of all snow layers; and $f_{i}$ is the fraction of total radiation absorbed by snow that is absorbed by layer $i$. The profile $f_{i}$ is evaluated from the profile of transmissivities $\tau_{s i}$ of each snowcover layer, which is a function of many factors including snow layer depth, density, snow grain size, and liquid water content. For simplicity, LEAF-2 currently parameterizes the transmissivity as

$$
\tau_{s i}=e^{-\epsilon D_{s} i},
$$

where $D_{s} i$ is snowcover depth (m) of layer $i$, and extinction coefficient $\epsilon$ is set to $20 \mathrm{~m}^{-1}$ based on an average value given in de Quervain (1973).

\section{g. Combining patch fluxes}

Each patch occupies a fractional horizontal area $A_{p}$ of a grid column in RAMS. Net momentum, moisture, sensible heat, longwave, and shortwave fluxes between the atmosphere and components of LEAF-2 are the integral of fluxes over all patches, weighted by the corresponding patch fractional areas. Once values of $u_{*}$, $T_{*}$, and $\chi_{*}$ for each of the patches are computed from surface layer similarity theory (Louis et al. 1981), an integrated surface layer momentum flux over all patches is computed from

$$
\begin{aligned}
& \overline{u^{\prime} w^{\prime}}=-\left(\frac{u}{\sqrt{u^{2}+v^{2}}}\right) \sum_{p=1}^{\mathrm{NP}} A_{p}\left(u_{*}^{2}\right)_{p} \text { and } \\
& \overline{v^{\prime} w^{\prime}}=-\left(\frac{v}{\sqrt{u^{2}+v^{2}}}\right) \sum_{p=1}^{\mathrm{NP}} A_{p}\left(u_{*}^{2}\right)_{p},
\end{aligned}
$$

and the average temperature and water vapor fluxes are

$$
\begin{aligned}
& \overline{w^{\prime} T^{\prime}}=\sum_{p=1}^{\mathrm{NP}} A_{p}\left(u_{*} T_{*}\right)_{p} \quad \text { and } \\
& \overline{w^{\prime} \chi^{\prime}}=\sum_{p=1}^{\mathrm{NP}} A_{p}\left(u_{*} \chi_{*}\right)_{p},
\end{aligned}
$$

where NP is the number of patches within a grid column, $(u, v)$ are horizontal velocity components, $w$ is vertical velocity, $T$ is temperature, and $\chi$ is vapor mixing ratio of the lowest atmospheric model level, primes denote turbulent fluctuations from local mean values, and overbars denote averages of turbulent fluctuations.

\section{h. Numerical integration}

Conservation equations for heat and moisture are solved explicitly for all LEAF-2 components, making computation very efficient. Numerical stability requires that the heat and water storage capacity of each component of the system be sufficiently large. For the soil, assuming a timestep of $2 \mathrm{~min}$, this translates to requiring a minimum thickness around $3 \mathrm{~cm}$ for each layer. For snowcover, a minimum thickness of $1 \mathrm{~cm}$ appears to be more than adequate, and this fact is used to help determine the number of layers used in representing snowcover. For vegetation and canopy air, particularly where vegetation is sparse or shallow, storage capacities may be too low for stable computational solutions unless the model timesteps are short. We thus impose an artificial lower bound on values of heat and moisture storage capacity of canopy air and heat capacity of vegetation where their natural capacities are too low. The artificial capacities are normally just large enough for stable numerical integration, which means that vegetation and canopy air respond quickly (on the timescale of a single time step) to changes in the system, and the added heat and moisture that they can store is minimal. The conservation property of flux equations is maintained with this method.

\section{i. Defining vegetation parameters}

LEAF-2 currently uses the BATS (Biosphere-Atmosphere Transfer Scheme) (Dickinson et al. 1986) vegetation classes to define many of its parameters, although the physical processes represented in BATS are not used. The vegetation parameters adopted from BATS include the leaf area index, fractional coverage, displacement height, roughness height, albedo, and emissivity. Of these, the leaf area index and fractional coverage have a simple seasonal dependence. Other vegetation characteristics, including stomatal parameters, heat storage capacity, and root-zone depth must also be specified. Independent specification of each of these parameters is optional when available data warrant.

The standard data source for initializing vegetation classes and other land use characteristics in LEAF-2 is the Global Ecosystems dataset (Olson 1994a,b), which is archived at the EROS Data Center. A total of 94 ecosystem classes are defined on a grid with approximately 1-km spacing. For RAMS, these data have been reprojected onto a latitude-longitude grid with 30-arcsecond spacing. Currently, the 94 ecosystem classes are cross referenced to the 18 BATS classes for which physical parameters required in LEAF-2 have been defined. Some additional information is extracted from the original 94 classes to define more than just the BATS vegetation class for a patch. For example, two different Global Ecosystems classes may be referenced to the same BATS class where one is swamp or marsh land and the other is not. LEAF-2 distinguishes between the 
two, defining a separate patch for each. The swamp patch is initialized with saturated soil and surface water, while the other is not. Thus, LEAF-2 defines a standard set of $L$ patch types somewhat larger in number than the 18 BATS classes, but fewer than the 94 Global Ecosystems classes. The user selects the number $P$ of distinct patches per grid cell to be defined from the input dataset, and LEAF-2 automatically fills those patches with the $P$ most frequently occurring ecosystem classes out of the $L$ LEAF-2 classes.

Work is planned at the Natural Resource Ecology Laboratory at Colorado State University to define physical parameters, such as leaf area index, fractional coverage, albedo, root profile, and roughness height, for each of the 94 Global Ecosystem classes rather than cross referencing to the 18 BATS classes. This will allow greater flexibility in the automatic definition of these parameters worldwide.

In current research, LEAF-2 has been coupled with plant growth models CENTURY (Parton 1996), and GEMTM (Chen and Coughenour 1994). These models provide dynamic values of plant physical parameters to LEAF-2 in response to meteorological and soil water predictions from RAMS and LEAF-2. This interactive system provides a tool that can be used to estimate the long-term ecosystem change and the interaction between ecosystem and climate in long-term climate prediction.

\section{TOPMODEL formulation and implementation in LEAF-2}

TOPMODEL is a catchment-scale hydrological model that represents lateral (horizontal) redistribution of groundwater due to gravity-driven downslope flow. It is most relevant to soil moisture within a meter or two of the surface, which is the moisture that supplies most daily evapotranspiration. Subsurface transport of water described by TOPMODEL occurs over a characteristic horizontal distance scale of tens to hundreds of meters, which is smaller than the horizontal grid spacing used in most RAMS applications. Thus, in coupling TOPMODEL with LEAF-2, water is redistributed between subgrid patches. There is no assumed spatial relation between the patches, and an individual patch may represent several highly elongated and disconnected areas.

The major effects of applying TOPMODEL are twofold. First, while precipitation is supplied to the ground uniformly over a local (RAMS grid cell) area, TOPMODEL causes relative drying of the soil in some subregions (patches) of the cell, while replenishing soil moisture in others. Second, TOPMODEL provides a means for draining soil moisture into stream beds where it can be carried away, leading to net drying of the local area. In geographic regions where there is negligible terrain slope at scales of tens of meters, or where arid conditions prevail and soil is not saturated, TOPMODEL has no effect.

Patches to which TOPMODEL is applied are clas- sified into groups, and water redistribution takes place within a group. A group may extend across adjacent grid cells, and more than one group may occupy a single grid cell. A group normally represents one or more small catchments, or local runoff areas inside which lateral distribution of water can occur. A patch represents collectively all areas within those catchments having a similar tendency to gain or lose water by lateral transport. Thus, one patch in a given group may represent areas near ridge tops where the soil rapidly dries following a precipitation event as groundwater flows downhill away from them, while another patch may represent low-lying areas that receive net groundwater input and retain abundant soil moisture for extended periods. Since patches are also defined in LEAF-2 in terms of vegetation type, patches may be defined as having a unique combination of vegetation type and wetness index. For example, a given group may have both a grassland and a forest patch for each hydrological tendency toward wetness or dryness.

Details of the physical processes and equations on which TOPMODEL are based are given in Beven and Kirkby (1979), Beven (1982), and Sivapalan et al. (1987). The flux of water in the soil is proportional to the saturated hydraulic conductivity, which is assumed to decrease exponentially with depth according to

$$
K_{s}(z)=K_{0} \exp (f z),
$$

where $K_{0}$ is the surface value of saturated hydraulic conductivity, $K_{s}$ and $K_{0}$ have units of meters per second, $f^{-1}$ is the (positive) $e$-folding depth (m) of $K_{s}$, and $z$ is negative of the depth $(\mathrm{m})$ of the water table, that is, $z$ $=0$ at the surface and decreases with depth. Beven $(1982,1984)$ has shown that this simple relation appears to be a reasonable approximation for a large number of soils based on measured conductivities at different depths. This hydraulic conductivity profile implies that moisture percolation is very slow beyond a certain depth in the soil, and that sufficient infiltrating precipitation or snowmelt will tend to form a perched water table, below which the soil is saturated and above which it is subsaturated.

TOPMODEL assumes that the water table is parallel to the ground surface; the slope $\tan \beta$ of the water table provides the differential head that drives lateral flux of water in the saturated zone. The total flux of water below the water table per unit topography contour length $\left(\mathrm{m}^{2}\right.$ $\mathrm{s}^{-1}$ ) is the product of $\tan \beta$ and the hydraulic conductivity integrated vertically from a large depth where conductivity vanishes to the height $z_{i}$, and can be written

$$
q=T_{0} \tan \beta \exp \left(f z_{i}\right)
$$

where $T_{0}=K_{0} f^{-1}$.

From Eq. (20) and the local topography, a long-term tendency for soil at a particular location to be wetter or drier than the local (catchment or group) average is derived by considering a situation of steady-state horizontally uniform recharging by precipitation at rate $R$ 
$\left(\mathrm{m} \mathrm{s}^{-1}\right)$. For any surface location, the upstream precipitation catchment area $a$ per unit topography contour length is identified. This is a distance [m] equivalent to the average length of unbroken hillslope above the given location. The flux $q$ at that location is equated with the product $a R$, and Eq. (20) is solved for the local value of $z_{i}$, which gives

$$
z_{i}=\frac{1}{f} \ln \left(\frac{a R}{T_{0} \tan \beta}\right) .
$$

Recharge rate $R$ is eliminated from this equation by integrating over the total area $A$ of the patch group, solving the integrated equation for $R$, and substituting the resulting expression into the above equation, which gives

$$
z_{i}=\overline{z_{i}}+\frac{1}{f}(W-\bar{W}),
$$

where

$$
\begin{aligned}
\overline{z_{i}} & =\frac{1}{A} \int_{A} z_{i} d A, \\
W & =\ln \left(\frac{a T_{e}}{T_{0} \tan \beta}\right), \\
\bar{W} & =\frac{1}{A} \int_{A} W d A, \quad \text { and } \\
\ln T_{e} & =\frac{1}{A} \int_{A} \ln T_{0} d A .
\end{aligned}
$$

The wetness index $W$ is a function of the local terrain slope, hydraulic conductivity, and upstream collection area, and $\bar{W}$ is an area average wetness index for the group; both are time-independent properties.

Equation (22) describes the steady state local height of the water table in terms of its area mean $\overline{z_{i}}$ and the deviation of the local wetness index from its area mean under conditions of spatially and temporally uniform precipitation recharging over the group. Most previous formulations of TOPMODEL are based on this steady state equation (e.g., Beven and Kirkby 1979; Band et al. 1993).

In order best to represent lateral groundwater transport in the coupled models, it must be recognized that RAMS and LEAF-2 explicitly treat transients of precipitation recharge and evapotranspiration loss of soil moisture. Furthermore, because initial runoff of heavy precipitation or snowmelt on sloping terrain redistributes water laterally before infiltration, and because infiltration and evapotranspiration rates both depend on soil moisture, net input or loss of water in the soil by vertical flux is not spatially uniform. Thus, the spatial and temporal constancy assumed for $R$ in deriving Eq. (22) is not valid in many instances and is not the general behavior in LEAF-2.
On the other hand, Eq. (22) represents a long-term relationship between topography (wetness index) and soil moisture that has been approximately verified in several field studies (e.g., Beven 1984, 1986; Hornberger et al. 1985; Famiglietti and Wood 1991). Furthermore, use of the wetness index to characterize longterm effects of lateral groundwater transport combines many dissimilar land areas [i.e., large terrain slope $\tan \beta$ and large upstream catchment area $a$ with small slope and catchment area: see Eq. (24)] into groups of similar wetness, which is far more efficient than treating dissimilar land areas individually. The alternative of explicitly routing groundwater down each of several slope configurations through sequences of spatially connected patches is computationally impractical for most applications.

Thus, we adopt Eq. (22) as a physically based (although idealized), observationally supported, and practical representation of lateral groundwater redistribution. Rather than apply the steady-state distribution of water instantaneously, we introduce a characteristic timescale $\mathcal{T}$, defined below in Eq. (29), over which groundwater redistribution occurs. In this form, TOPMODEL provides a redistribution rate rather than a steady-state distribution.

In the coupled models, this rate is evaluated and applied incrementally to each TOPMODEL time step $\Delta t_{T}$ in transferring groundwater between patches according to

$$
\frac{z_{i u}-z_{i c}}{\Delta t_{T}}=\frac{\left(z_{i}-z_{i c}\right)}{\mathcal{T}},
$$

where $z_{i c}$ and $z_{i u}$ are the current and updated model water table heights in a patch, and $z_{i}$ is the steady state value from TOPMODEL given by Eq. (22). Time step $\Delta t_{T}$ is normally about $1 \mathrm{~h}$, which is much shorter than $\mathcal{T}$ (although longer than the time step used in LEAF-2). Incremental application of TOPMODEL water distribution allows interaction between the models and accommodates transient and spatially inhomogeneous groundwater sources and sinks in LEAF-2.

In applying Eq. (27) in LEAF-2, patches are each preassigned an appropriate value of wetness index and fractional area within a group based on topographic and soil information. The group mean value of $\bar{W}$ is computed by summing over the individual $W$ values weighted by the fractional areas. The current value $z_{i c}$ of the water table height for each patch is diagnosed based on the prognostic soil water profile in LEAF-2. This is done by counting saturated soil levels up from the bottom and stopping before the first level that contains less moisture than $95 \%$ of saturation. Any small deficit (up to $5 \%$ ) in those saturated soil levels is accounted for when summing water in the column, and contributes to a small downward adjustment of computed $z_{i c}$ in order to exactly account for all water present. The current mean water table height $\overline{z_{i}}$ for the group is computed 
as the area-weighted sum of $z_{i c}$. Equations (22) and (27) return a $z_{i u}$ distribution which has the same mean value as $z_{i c}$ and thus conserve total water beneath the water table over a group.

The water content in the unsaturated zone above the water table is conserved both globally and in each patch by simply leaving it unchanged during TOPMODEL water table adjustment. For example, if the water table rises locally, the amount of water contained in a saturated zone of height $z_{i u}-z_{i c}$ is added to the entire column. This is done by saturating all unsaturated levels, starting from the bottom of the soil model, until the correct amount of water is added. If the water table falls locally, the amount of water contained in a saturated zone of height $z_{i c}-z_{i u}$ is subtracted from the entire column. This subtraction is made only from the uppermost saturated level. Because the increment $\Delta t_{T} / \mathcal{T}$ is very small, this never amounts to more than a few percent reduction in water content of that single level, and vertical water transport in LEAF-2 quickly adjusts to the removal over a much smaller time scale.

It is possible for lateral water redistribution to completely saturate the soil in a given patch and produce excess water above the ground surface known as saturation overland flow (SOF) (Dunne et al. 1975). Because LEAF-2 has a surface water category (which may consist of snowcover), this excess water is initially placed into that category. Runoff from the surface water category, whether it be from melting snow, rainfall that cannot immediately permeate into the soil, or SOF, is drained into a special bottomland patch, which is not a member of a patch group and does not participate in the TOPMODEL subsurface water redistribution described by Eq. (27). Thus, SOF that drains into a bottomland patch constitutes a net water loss for a group. The bottomland patch may represent a stream bed, from which water may be routed out of the patch and grid cell through a river system, or it may represent a lake or area with poor drainage that collects stagnant water with sufficient precipitation.

The lateral water flux in the saturated zone in Eq. (20) describes, in addition to redistribution within a catchment, a net loss of water from a catchment to a stream or bottomland known as baseflow. This is implied by the following equation which is obtained by combining Eqs. (21), (22), and (24),

$$
R=T_{e} \exp \left(f \overline{z_{i}}\right) \exp (-\bar{W}) .
$$

Here, $R$ may be interpreted as the precipitation rate required to maintain a steady water table height for a particular value of $\overline{z_{i}}$, or, equivalently, as the rate of net water loss (baseflow) in the absence of precipitation. This water removal contributes to a lowering of mean group water table height $\overline{z_{i}}$ at velocity $R / \eta_{s}$, where $\eta_{s}$ is the fractional volume that can be occupied by water.

The $e$-folding depth $f^{-1}$ divided by downward water table velocity provides a measure of the characteristic response time of TOPMODEL, which was used in Eq. (27) and is written with the help of Eq. (28) as

$$
\mathcal{T}=\frac{\eta_{s}}{f T_{e} \exp \left(f \overline{z_{i}}\right) \exp (-\bar{W})} .
$$

Here, $\mathcal{T}$ may be interpreted as the decay constant of baseflow which, in the absence of net input or loss of water from the surface, decreases exponentially in time. Equation (28) may be written in terms of $\mathcal{T}$ as

$$
R=\frac{\eta_{s}}{f \mathcal{T}}
$$

which illustrates the dependence of $R$ on $\mathcal{T}$. Baseflow water is removed from a patch group each TOPMODEL time step in the amount $R \Delta t_{T}$, similar to the application of (27), and is transferred to the bottomland patch of the group.

The term $f T_{e} \exp \left(f \overline{z_{i}}\right)$, which equals $K_{o} \exp \left(f \overline{z_{i}}\right)$ when saturated hydraulic conductivity does not vary horizontally, may vary by orders of magnitude depending on $z_{i}$ and the profile of saturated hydraulic conductivity, and is thus of paramount importance in determining the characteristic timescale $\mathcal{T}$ and, consequently, the rates of lateral water distribution and baseflow. Stieglitz et al. (1997) applied a coupled TOPMODEL-SVAT system to a relatively porous soil with $K_{o}=2.2 \times 10^{-3} \mathrm{~m} \mathrm{~s}^{-1}$ and $f=3.26 \mathrm{~m}^{-1}$. Assuming that $\bar{W}=8$, the value used in the present study, the above soil porosity leads to $\mathcal{T}=7$ days, 6 months, and 12 yr for $z_{i}=0,-1 \mathrm{~m}$, and $-2 \mathrm{~m}$, respectively. Subsurface lateral water transport should have an important influence on soil water distribution when it occurs at a timescale comparable to or less than the typical timescale for precipitation to supply the amount of moisture present in the soil. For many areas, this timescale is a few to several months. Thus, for a porous soil as the one studied in Stieglitz et al. (1997) and for $z_{i}$ within a meter or so of the surface, TOPMODEL should transport water rapidly enough to produce large horizontal inhomogeneities in the soil moisture supply. For much less porous soils and/or where $z_{i}$ is deeper in the soil, subsurface lateral water transport becomes very slow, the soil moisture budget is dominated by vertical transport, and horizontal inhomogeneities in soil moisture are not produced in significant measure by runoff described by TOPMODEL.

\section{Verification and sensitivity tests}

The original formulation of LEAF was tested and applied in Lee (1992) and Lee et al. (1995). Previous testing and verification of TOPMODEL were conducted by Beven (1984, 1986); Hornberger et al. (1985), and Famiglietti and Wood (1991). Recent applications of TOPMODEL coupled to a soil-vegetation-atmosphere transfer model are described in Famiglietti and Wood (1991, 1994, 1995), Band et al. (1993), Band (1993), and Stieglitz et al. (1997). 
The current implementation of LEAF-2 in RAMS was applied in simulations of the BOREAS Experiment (Vidale et al. 1997). Simulated model results compared well with both ground-based and aircraft measurements acquired during the experiment. Taylor et al. (1998) have applied LEAF-2 in RAMS simulations of snow breezes in the boreal forest. Pielke et al. (1999) used LEAF-2 in simulations of summertime sea breeze circulations and convective precipitation in south Florida to examine the effects of anthropogenic land use change since 1900. Model results showed approximately a $20 \%$ decrease in precipitation from then to the present, which is consistent with available rainfall data.

The primary purpose of this section is to demonstrate that simulated atmospheric conditions can respond significantly to the detail of the surface representation (i.e., the number of patches used) and to the inclusion of lateral transport of soil water between patches as described by TOPMODEL. We thus perform a set of sensitivity experiments with the RAMS/LEAF-2/TOPMODEL system whose setup designs differ only in the number of patches employed or in the use or nonuse of TOPMODEL. We focus on surface fluxes of heat and moisture, which are the most direct effect of the surface on the atmosphere, rather than on secondary effects on atmospheric systems. While the results presented are quantitative, they should be viewed more qualitatively in that the numerical experiments are idealized and are not intended to represent any specific event.

The first set of simulations, numbered 1-4, are twodimensional representations of an island $200 \mathrm{~km}$ wide in the ocean. A grid spacing of $20 \mathrm{~km}$ is used for the island and nearby ocean region, while a coarser grid with spacing $100 \mathrm{~km}$ is used over a more distant, much larger, ocean region. Middle latitude summertime conditions with a cloudless sky are used, with zero initial wind. Vertical turbulent transport in the atmospheric column is parameterized using the Mellor and Yamada (1982) level 2.5 formulation. The model soil (sandy clay loam) is initially completely saturated and gradually dries through surface evaporation and transpiration over the simulation period of 50 days. Bedrock is assumed to begin $60 \mathrm{~cm}$ below the surface. The ocean surrounding the island is assigned a relatively cool surface temperature of $15^{\circ} \mathrm{C}$ so that air advecting over the island stays relatively dry to aid in drying the soil. Sea breezes develop within the first few hours, and as the island under the summer sun gradually warms relative to the cool ocean, the sea breezes persist for the remainder of the simulations. Because the atmosphere is allowed to respond to surface forcing, atmospheric feedback to surface conditions occurs in these simulations to some extent. However, in all simulations, atmospheric winds, temperatures, and humidity values were fairly similar due to strong influence of the extensive ocean surface.

Simulation 1 is carried out with a single land patch characterized by short grass in each island grid cell. Simulation 2 is like simulation 1 except that a deciduous
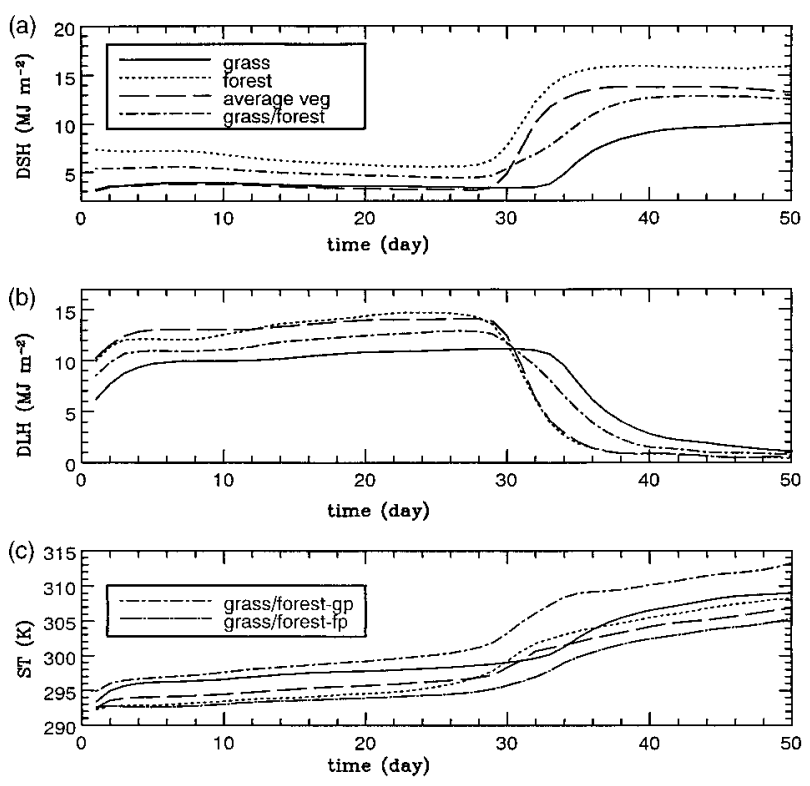

FIG. 2. Comparative results from simulations 1-4. Top panel: dailyaveraged sensible heat flux; middle panel: daily-averaged latent heat flux; bottom panel: daily maximum temperature of top soil layer. Line labels in top panel apply to all panels. Line labels in bottom panel apply to bottom panel only and distinguish between the grass patch and forest patch of the combined grass/forest simulation.

forest is used in place of grass. Simulation 3 uses two land patches of equal area in the island grid cells, one with grass and the other with deciduous forest. Simulation 4 uses a single land patch with vegetation characteristics (albedo, longwave emissivity, displacement and roughness heights, LAI, fractional coverage, and rooting depth) averaged between values for grass and deciduous forest.

Time series of surface sensible and latent heat fluxes averaged over each day and over the island from simulations 1-4 are shown in Fig. 2. All cases begin with low sensible and high latent heat flux due to the saturated soil, but reverse to high sensible and low latent heat flux by the end of the simulation when the soil has become dry. Simulation 2 with all forest cover always produces greater daytime sensible heat flux, and for the first 30 days greater latent heat flux as well, than simulation 1 with all grass cover. The greater total energy flux is due in part to the lower albedo of the forest (15\% compared with $26 \%$ for grass), causing more solar energy to be absorbed by the canopy. Another reason is illustrated in Fig. 2 (bottom panel), which shows the daily maximum temperature of the uppermost soil layer, averaged over all island grid cells, for simulations 1-4. With grass, a higher average surface temperature is produced, which causes more rapid heat flux toward the deeper layers of soil.

The greater latent heat flux in the forest case causes the soil to dry out more quickly, with the consequence that latent heat flux in simulation 2 drops off with time sooner than in simulation 1 . Thus, after day 30 , the grass 
case produces more latent heat flux, although it later reduces to near the forest value by day 50. The earlier drying of the soil in the forest case causes the daytime sensible heat flux to reach its dry-soil plateau several days earlier than in the grass case. The greater sensible heat flux of the forest case causes a greater diurnal variation and long-term upward trend in average surface air temperature over the island such that daytime high temperature becomes about $5 \mathrm{~K}$ greater than in the grass case by the end of the simulation (not shown).

Simulation 3, with equal partitioning of the island grid cells into grass and forest, produces, in many respects, a solution that is close to an average between simulations 1 and 2. Initial and final sensible and latent heat fluxes are approximately halfway between the extreme values of the grass-only and forest-only cases, and the transition in fluxes between the moist and dry soil regimes occurs at a time roughly halfway between the transitions in those cases.

However, in some ways, simulation 3 produces more extreme values. Figure 2 (bottom panel) shows the daily maximum temperature of the uppermost soil layers averaged separately over all grass patches and over all forest patches. The grassy patches reach higher daily maximum temperatures by a few degrees than in simulation 1, while the forested patches remain at cooler daily maximum temperatures than in simulation 2 . The reason for this is that the air over the grassy patches in simulation 3 is heated more than in simulation 1 because it interacts partly with forest whose sensible heat flux is higher than that of grass. The warmer air, compared to simulation 1, leads to warmer soil beneath the grass. Similarly, air over the forested patches in simulation 3 is heated less than in simulation 2 because it interacts partly with grassy patches; this cooler air leads to cooler soil beneath forested areas than in the all-forest case. Vegetation temperature (not shown) exhibits a similar response for the same reason. The highest and lowest maximum daytime vegetation temperatures occur in the grass and forest patches, respectively, of simulation 3 .

Simulation 4 does not produce the same grid-averaged response as simulation 3, as might be expected, even though both have the same grid-cell average of vegetation characteristics. Reduction of sensible heat flux and increase of latent heat flux as the soil dries is fairly abrupt, as in simulations 1 and 2, while in simulation 3, the transition is much more gradual as the soils in the grass and forest patches dry at different times. Moreover, simulation 4 has a sensible heat flux close to that for grass and a latent heat flux close to that for forest during the period when soil is moist. Thus, while the total energy flux is similar to simulation 3, an approximate average of simulations 1 and 2, the Bowen ratio is different from simulation 3. Simulation 4 also does not produce the extreme soil temperature values of the individual grass and forest patches of simulation 3 which, while not representing much difference in average conditions for the grid cell, become important when one is concerned with the response of the local ecosystem in each patch.

These simulations demonstrate important advantages of allowing subgrid patch representation in the model. One advantage concerns models that must select among given defined vegetation types to characterize an entire grid cell. In such models, if the actual land surface area covered by a grid cell is not primarily covered by a single land use type but contains a large percentage of two or more types, characterization of the region by a single land use type can significantly bias the simulation results, as seen in the differences between simulation 3 and simulations 1 or 2 . The case could be even worse if, say, five different surface types equally covered a grid cell and the model were required to choose one of them to characterize the entire cell. A second advantage concerns models that are able to utilize grid-cell-averaged vegetation properties. Comparison of simulations 3 and 4 has shown that not only are the conditions of individual vegetation regions (patches) not correctly simulated, but grid-cell averaged properties may also differ significantly.

Simulations 5-7 are more idealized than simulations 1-4 in that atmospheric conditions are held constant in time in order to isolate the direct influence of the surface on fluxes to the atmosphere. Solar radiation undergoes seasonal change, however, beginning the first day of spring and lasting for the 180-day period of the simulations. As before, soil is initialized as completely saturated, but this time extends deeper $(2 \mathrm{~m})$ before reaching bedrock. Only a single column (grid cell) of soil needs to be represented in this case, although seven land patches of equal area are included. Patch wetness index values are arbitrarily chosen to range from 3 to 13 in uniform increments. These values are representative of topography of significant slope where runoff is rapid, and are chosen to illustrate a situation where TOPMODEL's influence is large. All patches are assumed to be covered with short grass. Simulation 5 is carried out without TOPMODEL, and all patches thus have identical responses in time. Simulation 6 utilizes TOPMODEL, and baseflow and saturation overland flow both accumulate in the bottomland patch and stagnate there. Simulation 7 is like simulation 6 except that stream flow is assumed to immediately carry away any surface water from the bottomland patch.

Figure 3 is a plot of soil moisture as a function of depth at day 5 of the simulation for each of the seven land patches. The top panel depicts results without TOPMODEL, where all patches have identical values. The influence of TOPMODEL in the middle and lower panels causes widely varying drying rates between patches. Figures 4 and 5 compare patch moisture profiles at days 70 and 120, respectively. At day 70, patches in the TOPMODEL cases range widely in moisture content at the surface, especially in the middle panel where the bottomland patch remains fully saturated and contains surface standing water. The no-TOPMODEL case remains 

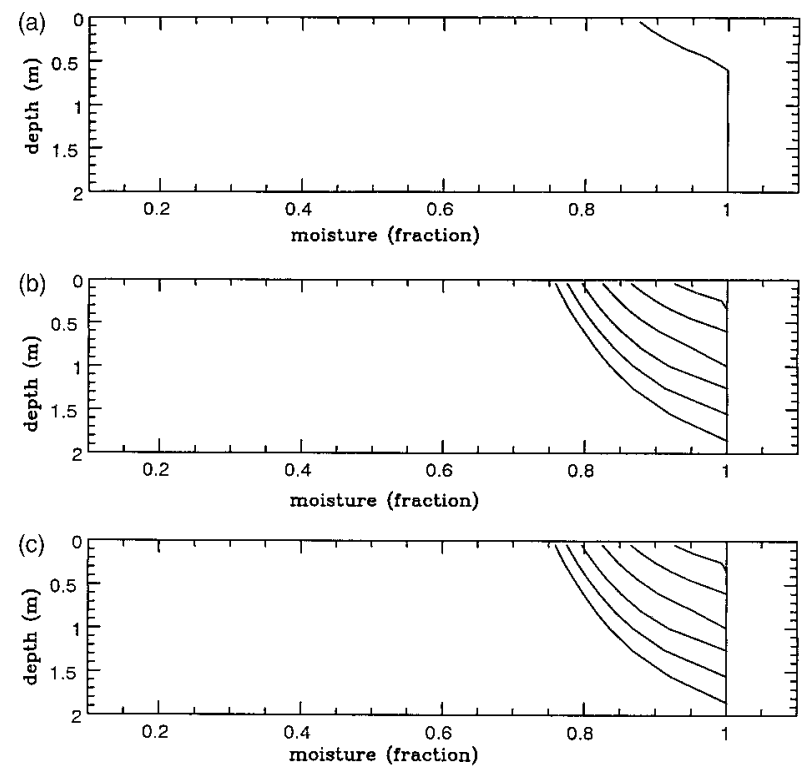

FIG. 3. Soil moisture fraction versus soil depth for seven land patches at day 5 of the simulation. Top panel: simulation 5, which has no TOPMODEL; middle panel: simulation 6 , which has TOPMODEL and no runoff from bottomland patch; bottom panel: simulation 7, which has TOPMODEL and immediate runoff of surface water from bottomland patch.

moderately moist at the surface at this time. At day 120 , all patches in all cases have become dry except for the bottomland patch of the middle panel in which surface water finished evaporating only a short time before.

Figure 6 shows the surface sensible and latent heat fluxes averaged over the grid cell area and over each day as a function of time in the three simulations. All simulations have similar fluxes for the first 40 days
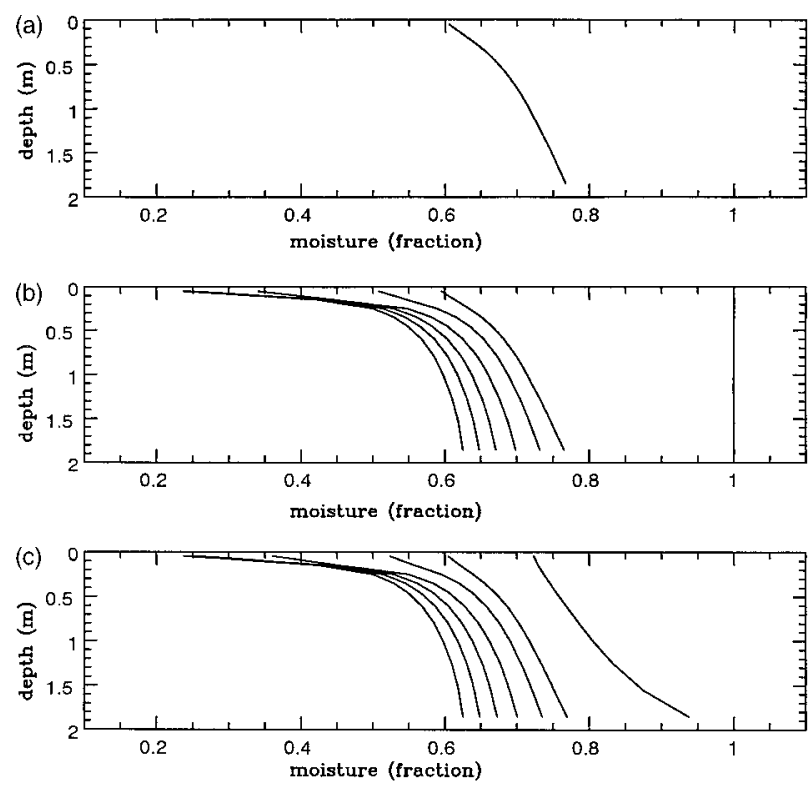

FIG. 4. Same as Fig. 3, except that time is day 70.
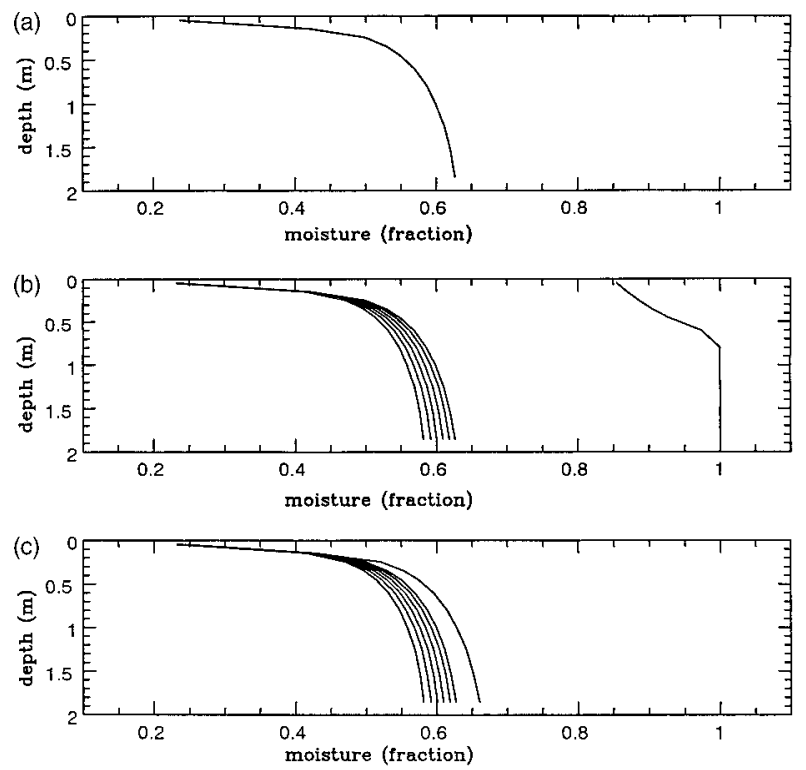

FIG. 5. Same as Fig. 3, except that time is day 120.

while soil moisture remains sufficiently high in all patches to evaporate nearly as readily as for saturated soil. From day 40 to nearly day 80 , all patches in simulation 5 remain wet enough to not depress surface moisture flux, whereas individual patches in simulations 6 and 7 dry enough for soil water potential to drop significantly and reduce grid-averaged moisture flux. As a result, sensible heat flux increases. All patches in simulation 5 reach this level of drying simultaneously and fairly abruptly near day 80 , and the sensible and latent fluxes consequently undergo large changes at this time.
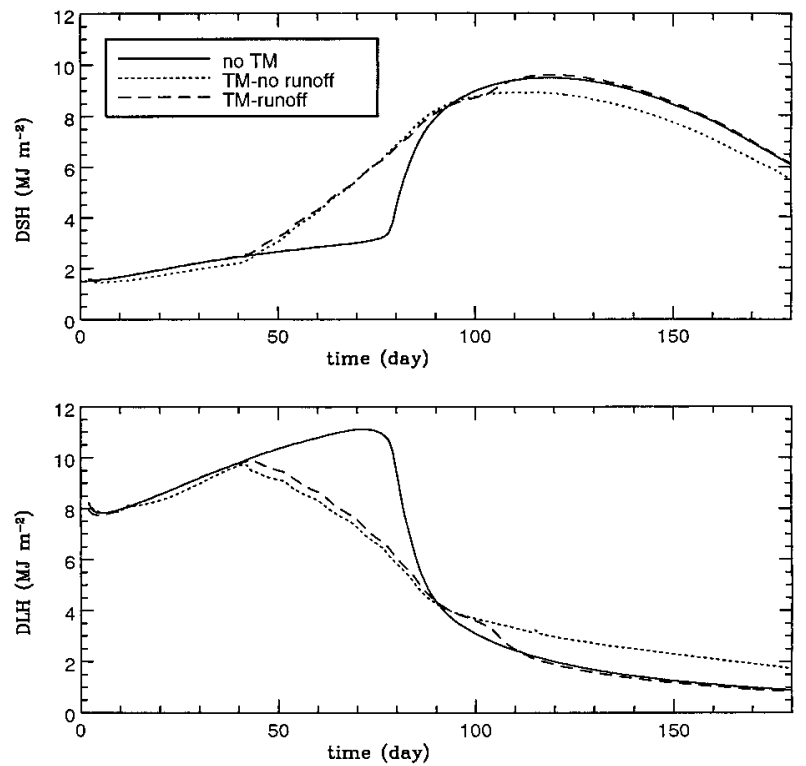

FIG. 6. Comparative results from simulations 5-7. Top panel: dailyaveraged sensible heat flux; bottom panel: daily-averaged latent heat flux. 
At day 90, latent heat flux in simulation 5 falls below values for simulations 6 and 7 as the latter retain some surface area with moist soil or standing water. By day 110 , the bottomland patch in simulation 7 has finally dried at the surface, and fluxes begin to match those of simulation 5. Abundant surface water in the bottomland patch of simulation 6 , however, maintains a larger latent and lower sensible heat flux for the remainder of the simulation.

It should be noted that, even though the assumed initial soil saturation in all patches effectively erased any influence that TOPMODEL might have exerted on soil water prior to the time of initialization, significant effects of TOPMODEL began to appear after only 40 days and persisted long after. Simulations initialized from realistic soil moisture in which the TOPMODEL effect has been active and where the driest patches have not saturated (from heavy precipitation) would begin with inhomogeneous distributions and the TOPMODEL effect on fluxes would be present from the start.

\section{Final comments}

The coupled LEAF-2/TOPMODEL system is the latest representation of soil and biophysical processes that has come into standard usage in RAMS. This paper is intended in part as an updated description of the model physics and equations that can be referenced in diverse model applications. Ongoing research in coupling this system with plant growth models such as CENTURY and GEMTM and to stream and river flow models will increase the model's applicability to long-term climate studies.

Sensitivity experiments were performed that demonstrate some important advantages of subgrid patch representation, which is a relatively recent addition to LEAF-2. Among these are definition and individual treatment of multiple land-use classes within a grid cell and the ability explicitly to represent small-scale inhomogeneity in soil moisture.

TOPMODEL was implemented into LEAF-2 such that it produces a redistribution rate of soil moisture between patches rather than an immediate redistribution. This was justified on physical grounds, based on the actual speed of saturated flow in the soil, and from the knowledge that soil moisture input and output can be very inhomogeneous within a catchment, violating an assumption made for steady-state versions of TOPMODEL. Sensitivity experiments with this implementation that began with horizontally homogeneous soil moisture showed that TOPMODEL had a significant effect not only in producing subgrid inhomogeneity of soil moisture but also on the grid-cell-averaged surface fluxes of sensible and latent heat.

Acknowledgments. We would like to acknowledge support provided by the National Park Service Contract CA 1268-2-9004 COLR-R92-0204 and the National
Aeronautics and Space Administration Grant NAG81511. TGFK is supported by the National Center for Atmospheric Research, which is supported by the National Science Foundation. We would like to thank Dallas McDonald for handling the final editing and preparation of the manuscript.

\section{REFERENCES}

Acs, F., 1994: A coupled soil-vegetation scheme: Description, parameters, validation, and sensitivity studies. J. Appl. Meteor., 33, 268-284.

Adams, E. E., and R. L. Brown, 1983: Metamorphism of dry snow as a result of temperature gradient and vapor density differences. Ann. Glaciol., 4, 3-9.

Avissar, R., 1995: Recent advances in the representation of landatmosphere interactions in general circulation models. Rev. Geophys., 33 (Suppl.), 1005-1010.

_ , and R. A. Pielke, 1989: A parameterization of heterogeneous land surfaces for atmospheric numerical models and its impact on regional meteorology. Mon. Wea. Rev., 117, 2113-2136.

_ - P. Avissar, Y. Mahrer, and B. Bravdo, 1985: A model to simulate response of plant stomata to environmental conditions. Agric. For. Meteor., 64, 127-148.

Band, L. E., 1993: Effect of land surface representation on forest water and carbon budgets. J. Hydrol., 150, 749-772.

_, P. Patterson, R. Nemani, and S. W. Running, 1993: Forest ecosystem processes at the watershed scale: Incorporating hillslope hydrology. Agric. For. Meteor., 63, 93-126.

Baron, J. S., M. D. Hartman, T. G. F. Kittel, L. E. Band, D. S. Ojima, and R. B. Lammers, 1998: Effects of land cover, water redistribution, and temperature on ecosystem processes in the South Platte Basin. Ecol. Appl., 8, 1037-1051.

Beven, K. J., 1982: On subsurface stormflow: An analysis of response times. Hydrol. Sci. J., 27, 505-521.

, 1984: Infiltration into a class of vertically non-uniform soils. Hydrol. Sci. J., 29, 424-434.

_, 1986: Hillslope runoff processes and flood frequency characteristics. Hillslope Processes, A. D. Abrahams, Ed., Allen and Unwin, 187-202.

_ uting area model of basin hydrology. Hydrol. Sci. Bull., 24, 4369.

Bosilovich, M., and W. Sun, 1995: Formulation and verification of a land surface parameterization for atmospheric models. Bound.Layer Meteor., 73, 321-341.

Charnock, H., 1955: Wind stress on a water surface. Quart. J. Roy. Meteor. Soc., 81, 639-640.

Chase, T. N., R. A. Pielke Sr., T. G. F. Kittel, J. S. Baron, and T. J. Stohlgren, 1998: Potential impacts on Colorado Rocky Mountain weather and climate due to land use changes on the adjacent Great Plains. J. Geophys. Res., 104, 16 673-16 690.

Chen, D., and M. B. Coughenour, 1994: GEMTM: A general model for energy and mass transfer of land surfaces and its application at the FIFE sites. Agric. For. Meteor., 68, 145-171.

Clapp, R. B., and G. M. Hornberger, 1978: Empirical equations for some soil hydraulic properties. Water Resour. Res., 14 (4), 601604.

Deardorff, J. W., 1978: Efficient prediction of ground surface temperature and moisture, with inclusion of a layer of vegetation. J. Geophys. Res., 83 (C4), 1889-1903.

de Quervain, M. R., 1973: Snow structure, heat, and mass flux through snow. IAHS Report 107, Vol. 1, WMO, 1484 pp.

Dickinson, R. E., 1995: Land-atmosphere interaction. Rev. Geophys., 33 (Suppl.), 917-922.

, A. Henderson-Sellers, P. J. Kennedy, and M. F. Wilson, 1986: Biosphere-Atmosphere Transfer Scheme for the NCAR Community Climate Model. NCAR Tech. Rep. NCAR/TN- 
275+STR, 69 pp. [Available from NCAR, P.O. Box 3000, Boulder, CO 80307-3000.]

Dunne, T., T. R. Moore, and C. H. Taylor, 1975: Recognition and prediction of runoff-producing zones in humid regions. Hydrol. Sci. Bull., 20 (3), 305-327.

Famiglietti, J., and E. F. Wood, 1991: Evapotranspiration and runoff for large land areas: Land surface hydrology for atmospheric general circulation models. Surv. Geophys., 12, 179-204.

— and energy balance processes. Water Resour. Res., 30, 30613078.

— , and — 1995: Effects of spatial variability and scale on areally-averaged evapotranspiration. Water. Resour. Res., 31 (3), 699-712.

Garratt, J. R., 1992: The Atmospheric Boundary Layer. Cambridge University Press, $316 \mathrm{pp}$.

Hornberger, G. M., K. J. Beven, B. J. Cosby, and D. E. Sappington, 1985: Shenandoah watershed study: Calibration of a topographically based, variable contributing area hydrological model to a small forested catchment. Water Resour. Res., 21, 1841-1850.

Lee, T. J., 1992: The impact of vegetation on the atmospheric boundary layer and convective storms. Atmospheric Science Paper No. 509, Colorado State University, Fort Collins, CO, 137 pp. [Available from Dept. of Atmospheric Science, Colorado State University, Fort Collins, CO 80523.]

— humidity. J. Appl. Meteor., 31, 480-484.

,-- , and P. W. Mielke Jr., 1995: Modeling the clear-sky surface energy budget during FIFE87. J. Geophys. Res., 100, 25 58525593.

Louis, J. F., M. Tiedke, and J.-F. Geleyn, 1981: A short history of the PBL parameterization at the ECMWF. Proc. Workshop on Planetary Boundary Layer Parameterization, Shinfield Park, Reading, United Kingdom, ECMWF, 59-80.

Loveland, T. R., J. W. Merchant, D. O. Ohlen, and J. F. Brown, 1991: Development of a land-cover characteristics database for the conterminous U.S. Photogramm. Eng. Remote Sens., 57, $1453-$ 1463.

Mahrer, Y., and R. A. Pielke, 1977: A numerical study of the airflow over irregular terrain. Contrib. Atmos. Phys., 50, 98-113.

McCumber, M. C., and R. A. Pielke, 1981: Simulation of the effects of surface fluxes of heat and moisture in a mesoscale numerical model, Part I: Soil layer. J. Geophys. Res., 86 (C10), 9929-9938.

Mellor, G. L., and T. Yamada, 1982: Development of a turbulence closure model for geophysical fluid problems. Rev. Geophys. Space Phys., 20 (4), 851-875.

Meyers, M. P., R. L. Walko, J. Y. Harrington, and W. R. Cotton, 1997: New RAMS cloud microphysics parameterization. Part II: The two-moment scheme. Atmos. Res., 45, 3-39.

Mihailovic, D. T., R. A. Pielke Sr., B. Rajkovic, T. J. Lee, and M. Jeftic, 1993: A resistance representation of schemes for evaporation from bare and partly plant-covered surfaces for use in atmospheric models. J. Appl. Meteor., 32, 1038-1054.

Noilhan, J., and S. Planton, 1989: A simple parameterization of land surface processes in meteorological models. Mon. Wea. Rev., 117, 536-549.

Olson, J. S., 1994a: Global ecosystem framework—definitions. USGS EROS Data Center Internal Report, Sioux Falls, SD, 37 pp.
[Available from Customer Services, U.S. Geological Survey, EROS Data Center, 47914 252nd St., Sioux Falls, SD 571980001.]

1994b: Global ecosystem framework-translation strategy. USGS EROS Data Center Internal Report, Sioux Falls, SD, 39 pp. [Available from Customer Services, U.S. Geological Survey, EROS Data Center, 47914 252nd St., Sioux Falls, SD 571980001.]

Parton, W. J., 1996: The CENTURY model. Evaluation of Soil Organic Matter Models, D. S. Powlson, P. Smith, and J. U. Smith, Eds., NATO ASI Series I, Vol. 38, Springer-Verlag, 283-291.

Pielke, R. A., T. J. Lee, J. H. Copeland, J. L. Eastman, C. L. Ziegler, and C. A. Finley, 1997: Use of USGS-provided data to improve weather and climate simulations. Ecol. Appl., 7, 3-21.

Pielke, R. A., Sr., R. Avissar, M. Raupach, H. Dolman, X. Zeng, and S. Denning, 1998: Interactions between the atmosphere and terrestrial ecosystems: Influence on weather and climate. Global Change Biol., 4, 101-115.

— R. L. Walko, L. Steyaert, P. L. Vidale, G. E. Liston, and W. A. Lyons, 1999: The influence of anthropogenic landscape changes on weather in south Florida. Mon. Wea. Rev., 127, 16631673.

Pleim, J., and A. Xiu, 1995: Development and testing of a surface flux and planetary boundary layer model for application in mesoscale models. J. Appl. Meteor., 34, 16-32.

Sellers, P., Y. Mintz, Y. Sud, and A. Dalcher, 1986: A simple biosphere model $(\mathrm{SiB})$ for use within general circulation models. J. Atmos. Sci., 43, 505-531.

Sivapalan, M., K. Beven, and E. F. Wood, 1987: On hydrologic similarity: 2. A scaled model of storm runoff production. Water Resour. Res., 23 (12), 2266-2278.

Stieglitz, M., D. Rind, J. S. Famiglietti, and C. Rosenzwieg, 1997: An efficient approach to modeling the topographic control of surface hydrology for regional and global climate modeling. $J$. Climate, 10, 118-137.

Stohlgren, T. J., T. N. Chase, R. A. Pielke, T. G. F. Kittel, and J. S. Baron, 1998: Evidence that local land use practices influence regional climate, vegetation, and stream flow patterns in adjacent natural areas. Global Change Biol., 4, 495-504.

Taylor, C. M., R. J. Harding, R. A. Pielke Sr., P. L. Vidale, and R. L. Walko, 1998: Snow breezes in the boreal forest. J. Geophys. Res., 103, 23 087-23 101.

Tremback, C. J., and R. Kessler, 1985: A surface temperature and moisture parameterization for use in mesoscale models. Preprints, Seventh Conf. on Numerical Weather Prediction, Montreal, PQ, Canada, Amer. Meteor. Soc., 355-358.

van Genuchten, M. T., 1980: A closed-form equation for predicting the hydraulic conductivity of unsaturated soils. Soil Sci. Soc. Amer. J., 44, 892-898.

Vidale, P. L., R. A. Pielke, A. Barr, and L. T. Steyaert, 1997: Case study modeling of turbulent and mesoscale fluxes over the BOREAS region. J. Geophys. Res., 102, 29 167-29 188.

Viterbo, P., and A. Beljaars, 1995: An improved land-surface parameterization scheme in the ECMWF model and its validation. $J$. Climate, 8, 2716-2748.

Walko, R. L., W. R. Cotton, M. P. Meyers, and J. Y. Harrington, 1995: New RAMS cloud microphysics parameterization. Part I: The single moment scheme. Atmos. Res., 38, 29-62. 